\title{
Erratum
}

\section{A Short and Simple Synthesis of 1-Deoxynojirimycin Derivatives from D-Glucose}

Ashim Roy, Basudeb Achari, Sukhendu B. Mandal* Synthesis 2006, 1035.

The synthesis of deoxynojirimycin derivatives from D-glucose requires a double inversion at C-5. In the paper cited above, we described a single inversion at C-5 and consequently, compounds $\mathbf{9 , 1 0}$ and 11 must be epimers at C-5 of the structures shown. Therefore, the title, abstract and structures of 9, 10, and $\mathbf{1 1}$ should be amended as follows:

Title: A Synthesis of 1-Deoxy-L-ido-nojirimycin Derivatives from D-Glucose

Abstract: Insertion of an amino functionality at C-5 of D-glucose with inversion of configuration, followed by imine formation with the latent aldehyde at $\mathrm{C}-1$ and concomitant reduction, furnished the 1-deoxy-L-ido-nojirimycin skeleton. Correct structures of compounds $\mathbf{9 , 1 0}$ and $\mathbf{1 1}$ are shown below:<smiles>OC[C@H]1NC[C@@H](O)C(O)[C@@H]1O</smiles>

9

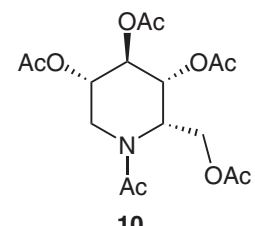

10<smiles>CC(=O)OC[C@H]1[C@H](OC(C)=O)C(O)CN(C(C)=O)[C@H]1OC(C)=O</smiles>

11

We would also like to point out that a closely related synthesis of 1-deoxynojirimycin from 5,6-anhydro-3-O-benzyl1,2-O-isopropylidene-L-ido-furanose has been described: Fleet, G. W. J.; Carpenter, N. M.; Petursson, S.; Ramsden, N. G. Tetrahedron Lett. 1990, 31, 409 (cited as reference 8b). 